\title{
Payment Restrictions for Prescription Drugs under Medicaid
}

\section{Citation}

Soumerai, Stephen B., Jerry Avorn, Dennis Ross-Degnan, and Steven Gortmaker. 1987. "Payment Restrictions for Prescription Drugs Under Medicaid." New England Journal of Medicine 317 (9) (August 27): 550-556. doi:10.1056/nejm198708273170906.

\section{Published Version}

doi:10.1056/NEJM198708273170906

\section{Permanent link}

http://nrs.harvard.edu/urn-3:HUL.InstRepos:32696176

\section{Terms of Use}

This article was downloaded from Harvard University's DASH repository, and is made available under the terms and conditions applicable to Other Posted Material, as set forth at http:// nrs.harvard.edu/urn-3:HUL.InstRepos:dash.current.terms-of-use\#LAA

\section{Share Your Story}

The Harvard community has made this article openly available.

Please share how this access benefits you. Submit a story.

Accessibility 


\title{
SPECIAL ARTICLE
}

\section{PAYMENT RESTRICTIONS FOR PRESCRIPTION DRUGS UNDER MEDICAID}

\author{
Effects on Therapy, Cost, and Equity \\ Stephen B. Soumerai, Sc.D., Jerry Avorn, M.D., Dennis Ross-Degnan, Sc.D., \\ and Steven Gortmaker, Ph.D.
}

\begin{abstract}
In an attempt to contain costs, 27 Medicaid programs have implemented patient-level payment limits for medications, but the effects of these restrictions on quality of care, costs, and health status remain largely unknown. We measured the effect of one state's limit of three paid prescriptions per month and its replacement a year later by a $\$ 1$ copayment. Using data on 48 months of claims in the study state (New Hampshire) and a comparison state (New Jersey), we employed time-series analysis to evaluate patient-level changes in the number of prescriptions filled for 16 drugs that varied in their clinical importance and cost.
\end{abstract}

Among 10,734 continuously enrolled patients, the limit of three paid prescriptions per month caused a sudden, sustained drop of 30 percent in the number of prescriptions filled (from 1.10 to 0.77 prescriptions per patient per month); no change was observed in the comparison state. The 860 recipients of multiple drugs, who were predominantly female and elderly or disabled, were most severely

$\mathrm{T}$ HE past several years have seen the implementation of diverse regulatory and financing changes aimed at reducing governmental costs for the health care of the poor and the elderly. ${ }^{1,2}$ In the Medicaid program, a variety of cost-limiting initiatives (e.g., curtailing eligibility for services, limiting coverage, and instituting copayments) have been put into effect by individual states since the Omnibus Budget Reconciliation Act of 1981. This act cut federal support for Medicaid programs but increased their administrative flexibility by allowing states to implement their own budget-reducing policies. ${ }^{3}$ Because of imperfections in the medical care marketplace, ${ }^{4}$ there is concern that such policies may result in reductions in essential as well as inessential care, adverse clinical outcomes, and increased costs, particularly among very ill and poor patients. One study demonstrated that when $186 \mathrm{pa}-$ tients with hypertension lost their Medicaid eligibility, their diastolic blood pressure increased by an average of $10 \mathrm{~mm} \mathrm{Hg} .{ }^{5}$ The Rand Health Insurance Experiment ${ }^{6-9}$ showed that cost sharing by patients who were not elderly reduced the number of medical care visits; this resulted in less favorable clinical outcomes only among patients with low incomes and hypertension

From the Department of Social Medicine and Health Policy, the Program for the Analysis of Clinical Strategies, and the Division on Aging, Harvard Medical School, and the Department of Behavioral Sciences, Harvard School of Public Health. Address reprint requests to Dr. Soumerai at the Program for the Analysis of Clinical Strategies, Harvard Medical School, 643 Huntington Ave., Boston, MA 02115.

Supported by grants from the Health Care Financing Administration (Cooperative Agreement No. 18-C-98496/1-01) and the National Center for Health Services Research (HSO 5554), U.S. Department of Health and Human Services. affected; the number of prescriptions per month dropped from 5.2 to 2.8 (46 percent). The decrease was greatest for "ineffective drugs" (58 percent), but large drops were also observed for "essential" medications, such as insulin (28 percent), thiazides (28 percent), and furosemide (30 percent). Reductions in Medicaid prescriptions were minimally offset by increases in the size of the prescription or in out-of-pocket payments.

When a \$1 copayment replaced the three-prescription cap, prescriptions for most medications increased to just below precap levels. Medicaid's savings on drug costs resulting from both policies were comparable $(\$ 0.4$ to $\$ 0.8$ million annually), but the copayment policy had less effect on patients receiving multiple drugs. Because the clinical consequences of such policies cannot be assessed from prescription data alone, further study is needed to determine the effects of cost-containment strategies on health status and the use of other services among poor populations. (N Engl J Med 1987; 317:550-6.)

and those with poor vision. ${ }^{7}$ However, because the study sample excluded elderly persons with low incomes, its results cannot easily be generalized to the most vulnerable population. For example, among 1322 low-income adults in the Rand experiment, only 10 patients used insulin, only 8 were taking betablockers, and only 54 used a diuretic. ${ }^{8}$

Our investigation evaluated the effect of two costcontainment policies under Medicaid - one in which limits were placed on the number of drug prescriptions reimbursed per month (drug "caps"), and one that required copayments by patients of a portion of the cost of medication. Because these policies do not account for differences in the severity of illness, they are simple to implement and administer; not surprisingly, one or both strategies had been adopted by 27 states by $1984 .^{10}$

As is true of other forms of therapy, there are great variations in cost and efficacy among the many pharmaceutical agents on the market. ${ }^{4}$ Because 60 percent of all visits to physicians result in the writing of one or more prescriptions, ${ }^{11}$ it is possible to study a large sample of therapeutic decisions in computerized claims data bases. ${ }^{12}$ Although there is broad agreement that overprescribing exists, ${ }^{13}$ it is clear that many drugs are highly cost effective in reducing both short-term and long-term morbidity and mortality.

The sudden implementation by New Hampshire Medicaid of a three-drug payment limit and its replacement 11 months later by a $\$ 1$ copayment policy provided a natural experiment in which to study the effect of these policies on access to medications by individual patients; their relative effects on the use of 
effective as opposed to "ineffective" drugs and on costly as opposed to less expensive agents; the extent of compensatory actions to maintain medication use (e.g., by increasing the size of prescriptions); and the economic effect of these policies on Medicaid and its recipients.

\section{MethodS}

\section{Research Design}

We used time-series analysis with comparison series ${ }^{14}$ to estimate the effects of the policy changes. In the study state (New Hampshire), we analyzed all drug prescriptions whose cost was reimbursed by Medicaid over a period of 48 months, including 20 months before the policy changes, 11 months during which the drug-cap policy was in effect, and 17 months after replacement of the drug cap by the copayment policy. Similar data from a comparison state (New Jersey) without such policies were analyzed to control for the possible influence of nationwide changes in prescribing trends.

\section{Study Interventions and Settings}

In July 1981, the state legislature of New Hampshire mandated that Medicaid implement several cost-control measures. Beginning September 1, 1981, the program for the first time restricted the number of prescriptions reimbursed to a maximum of three per patient per month. There was one important loophole in the regulation: the allowable quantity of tablets or capsules per prescription was tripled to a maximal three-month supply. Thus, with adequate communication among state officials, patients, pharmacists, and physicians, it was feasible to stagger prescriptions so that a patient could receive up to nine drugs, thus reducing the effect of the legislation.

Two months after the imposition of the cap, a legal challenge resulted in the exemption of patients in nursing homes, leaving only ambulatory patients subject to the cap. In August 1982, the cap policy was dropped completely and replaced by a copayment policy that required all outpatients to pay $\$ 1$ for each Medicaid prescription but placed no limits on the number of prescriptions allowed.

Apart from the policies just described, the study and comparison states had comparable Medicaid drug-reimbursement characteristics: neither state had a restrictive formulary; both programs provided reimbursement for most over-the-counter drugs; and pharmacy dispensing fees were comparable. ${ }^{11}$ The demographic characteristics of the two states were similar with regard to the relevant study variables.

\section{Data Sources}

The computerized Medicaid management information systems of the study and comparison states contain records of all prescriptions filled, collected as part of routine reimbursement activities. Each record identifies the product for which reimbursement was provided, the prescriber, the patient, the date the prescription was filled, the number of units dispensed, the dose per unit, the amount reimbursed, and the setting (e.g., outpatient or nursing home). A growing body of research indicates that in most Medicaid programs, prescription data are highly reliable and valid, even for individual drugs. ${ }^{12,15-18}$

Patient-specific enrollment files were also obtained to determine eligibility for Medicaid by month during the study period. These files also contained information on the age, sex, and category of eligibility of all Medicaid recipients.

All drug claims in New Hampshire were edited to eliminate duplicate claims; sorted according to recipient, date of dispensing, and drug code; and separated into subgroup files as described below. For the larger New Jersey data base, we extracted all claims for a 30 percent random sample of Medicaid recipients from July 1980 to December 1983 before sorting and separating them into subgroups. At no time were the identities of patients known to the investigators.
To evaluate possible compensatory out-of-pocket payments, all Medicaid and out-of-pocket prescription data were collected for 245 Medicaid patients who routinely received their medications at an independent pharmacy in southern New Hampshire. For patients who met the criteria for "multiple-drug recipients" as defined below, we recorded data on all prescriptions filled, regardless of the source of payment.

\section{Study Subgroups}

Before the start of analysis, we identified several subgroups of Medicaid recipients likely to be affected differently by the cap. Since patients in nursing homes were covered under the three-drug limit for only two months and were also exempted from copayments, they were excluded from the study. Within the population outside nursing homes, elderly, disabled, and chronically ill patients with high base-line medication use represent an important risk group. We defined one cohort of multiple-drug recipients as persons who had received an average of three or more prescriptions per month and at least one prescription every quarter in 1980. By defining the cohort on the basis of drug use in 1980, we were able to analyze prescription rates during the eight preintervention months in 1981 to control for possible regression toward the mean. No evidence of regression effects was found. ${ }^{19}$

To control for patient-specific changes in eligibility, moves out of the state, and deaths, we identified all Medicaid patients who were enrolled continuously for 10 or more months in each of the four years of study. This resulted in a sample of 10,734 continuously eligible patients in New Hampshire and 74,027 in New Jersey. To estimate the economic savings to Medicaid, we measured the dollar amounts reimbursed for all prescriptions for the entire Medicaid population.

\section{Outcome Variables}

We measured changes in the prescriptions filled, the units dispensed, and the drug costs reimbursed. To allow adjustment for changes in prescription size, we computed the number of units per prescription by month for all study groups and drugs. This made it possible to express use in terms of constant-size prescriptions or milligrams per patient, as well as to measure any compensatory changes in prescription use.

\section{Effective versus Ineffective Drugs}

We reviewed the literature on drug therapy to define drug groups that varied substantially in terms of efficacy, cost, and therapeutic importance. These were validated independently by a panel of internists, pharmacologists, and geriatricians using the $A M A$ Drug Evaluations $^{20}$ as background material. Effective drugs were subdivided into drugs whose withdrawal could have important effects on morbidity or mortality ("essential drugs"), and drugs prescribed primarily for symptomatic relief. Essential drugs included insulin, propranolol, thiazides (alone and with triamterene), furosemide, methyldopa, lithium, and digoxin. (Although digoxin is undoubtedly used by many patients who do not benefit from it, ${ }^{21}$ among the subset of patients who do require its inotropic or rate-controlling properties, some may have acute decompensation if it is withdrawn.)

Effective medications for symptomatic relief included several analgesics and antiinflammatory drugs: aspirin, acetaminophen, propoxyphene in combination with aspirin or acetaminophen, and ibuprofen. Medications with marginal or no efficacy were defined as those with only slight or no superiority over placebo for most commonly used indications. This group included ergoloid mesylates used for senile dementia, the barbiturate-anticholinergic combination agent Donnatal, propoxyphene without aspirin or acetaminophen, and the anticholinergic dicyclomine.

\section{Costly versus Inexpensive Drugs}

Drugs were divided into cost categories on the basis of average Medicaid payments to pharmacists. "Inexpensive" drugs were defined as those for which reimbursement averaged less than $\$ 6.50$ per 
month per recipient; "moderately expensive" drugs ranged in cost from $\$ 6.50$ to $\$ 10.00$; "expensive" drugs cost over $\$ 10.00$ per monthly supply.

\section{Statistical Analysis}

Mean monthly numbers of constant-size prescriptions and total milligrams per patient were plotted for the study groups. Regression models were fit to these time series with use of the SAS AUTOREG procedure. ${ }^{22,23}$ The models included a constant term, a linear time trend, and terms indicating changes in the mean level of prescribing during an "anticipatory" precap period (month 20) and the periods during which the cap (months 21 to 32 ) and the copayment (months 33 to 48 ) policies were in effect. Finally, terms were included for changes in linear time trend (slope) after the cap and the copayment policies were instituted. The statistical significance of the effects of the policy interventions was tested with t-statistics; correlated errors in the regressions were taken into account by assuming first-order autocorrelated errors. Because of the large number of patients and the reliability of the data, all effects reported are significant beyond the 0.05 level (and, in most cases, $\mathrm{P}<0.0001$ ).

\section{Results}

\section{Background Characteristics of Study Cohorts}

We identified a total population of 10,734 persons who were continuously enrolled in New Hampshire Medicaid and not residing in nursing homes during the study period. Seventeen percent of this group received no prescriptions during the study period. Multiple-drug recipients ( $\geqslant 3$ medications per month before the cap) represented only 8 percent of this group $(n=860)$, but had 47 percent of all the prescriptions filled in the base year (1980). As expected on the basis of their high use of medication, the members of this cohort were more likely to be elderly and disabled than other continuously enrolled patients. Their average age $( \pm S D)$ was $56 \pm 19$ years as compared with $33 \pm 26$ years for all other patients; the proportions over the age of 60 were 48 and 22 percent, respectively. The majority (81 percent) were female, as compared with 68 percent among other patients. The recipients of multiple drugs were eligible for Medicaid because of receipt of old-age assistance (36 percent), physical or mental disability (47 percent), or blindness (2 percent); 18, 20, and 1 percent, respectively, of all other patients were eligible for these reasons. Fourteen percent of multiple-drug recipients and 61 percent of all other patients received assistance from Aid to Families with Dependent Children. As expected, 87 percent of the high-use group were long-term recipients ( $\geqslant 4$ prescriptions per year before the cap) of one or more of the following classes of drugs: hypoglycemics (17 percent), cardiovascular agents (56 percent), bronchodilators ( 26 percent), anticonvulsants (12 percent), anticoagulants ( 2 percent), and medications for affective disorders ( 27 percent) or psychoses (26 percent)

\section{Effects on Total Prescriptions}

Monthly averages of constant-size prescriptions are plotted in Figure 1 for the two subgroups within the total population of continuously enrolled patients $(n=10,734)$ before and after implementation of the

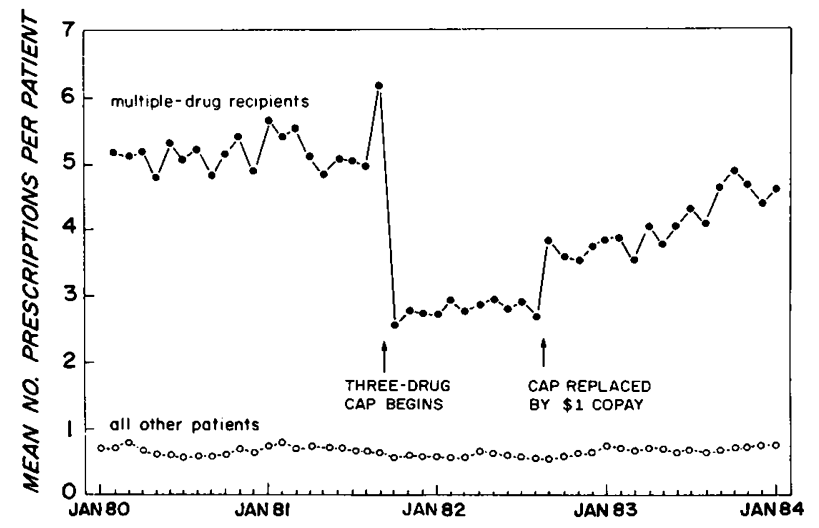

Figure 1. Time Series of Average Number of Constant-Size Prescriptions per Continuously Eligible Patient per Month among Noninstitutionalized Patients Receiving Multiple Drugs $(N=860)$ and Other Outpatients $(\mathrm{N}=8002)$.

Patients with no prescriptions throughout the four-year period $(n=1872)$ were excluded from the denominator.

cap and copayment policies. As expected, the greatest effects of these policies were concentrated among multiple-drug recipients $(n=860$; Fig. 1$)$. In the 20 months before the policy changes, this group had an average of 5.2 prescriptions filled per person per month. The cap caused an immediate and sustained reduction in the number of constant-size prescriptions of 46 percent ( 2.4 prescriptions per person per month) to an average level of 2.8 during the 11 -month cap period. There was no increase in medication use throughout the cap period. After the cap was replaced by a $\$ 1$ copayment, average prescription rates rose both in level and slope (Fig. 1) to approximately 4.7 constant-size prescriptions by the end of the 48-month period. The $\mathrm{R}^{2}$ for the regression equation was 0.96 , indicating a very good fit. All other patients had a much smaller, yet still significant, decrease of 17 percent in average number of Medicaid prescriptions filled, from their expected level of 0.7 per month; this rate increased significantly during the copayment period to approximately precap levels.

As shown in Figure 1, an anticipatory demand was observed for multiple-drug recipients in the month immediately before the cap was instituted; this effect was controlled for in all estimates.

In the New Jersey comparison series, drug-prescription rates among continuously enrolled outpatients remained stable at an average $( \pm \mathrm{SD})$ of $1.2 \pm 0.07$ prescriptions per patient throughout the entire study period, with very low month-to-month variations.

\section{Effects on Prescription Size}

Although the regulations allowed physicians to increase the number of units per prescription substantially in order to maintain the supply for their patients, the average prescription size among multiple-drug recipients increased by only 11 units per prescription (13 percent) during the cap period. There was no upward slope in prescription size during the cap period, sug- 
gesting that there was no "learning curve" for providers who did not compensate in the first several months. Prescription size decreased by 16 units per prescription to approximately precap levels soon,after the switch to the copayment policy. No such changes were observed for the comparison population.

\section{Withdrawal of Essential versus Inessential Drugs}

The cap policy had abrupt and significant downward effects on the rates of use of all 16 medications studied in the cohort of multiple-drug recipients, across all efficacy and cost categories. Among these patients, the switch to a copayment policy significantly increased prescription levels or trends for 9 of the 16 study-drug groups. During the cap period, essential drugs were relinquished at a somewhat lower rate than were less essential agents; within categories of efficacy, high-cost drugs were somewhat more likely to continue to be reimbursed than were the most inexpensive drugs. (All estimated effects reported below are in constant-size prescriptions per 100 patients per month.) The number of prescriptions filled for effective, essential medications declined from 67.0 to 48.6 (28 percent), that for effective symptomatic-relief drugs from 28.3 to 17.5 (38 percent), and that for drugs of limited efficacy from 5.5 to 2.3 ( 58 percent). Among essential medications, the number of prescriptions filled for inexpensive ones declined from 19.4 to 12.2 (37 percent), that for moderately expensive ones from 19.0 to 13.7 (28 percent), and that for expensive agents from 28.6 to 22.7 (21 percent).

The largest reductions in the actual numbers of prescriptions were for several commonly used essential medications; the reduction was from 11.6 to 8.4 prescriptions per 100 patients per month for insulin (28 percent), from 12.1 to 8.5 for furosemide ( 30 percent), from 9.0 to 6.5 for thiazide diuretics (28 percent), and from 10.4 to 5.7 for digoxin (45 percent). Across all efficacy categories, prescriptions for medications with the lowest cost declined from 30.2 to 16.4 (46 percent), prescriptions for moderately expensive agents decreased from 30.1 to 21.0 ( 30 percent), and those for expensive agents from 40.5 to 31.1 (23 percent). Prescriptions for aspirin and acetaminophen, which are available over the counter, dropped from 7.0 to 2.8 (61 percent), but the use of prescription analgesics fell only from 28.3 to 17.5 ( 31 percent). Thus, both increased drug cost and greater efficacy appeared to be independently associated with reduced effects of the cap.

\section{Patient-Level Effects on Insulin Use}

Because of the large decreases in the use of effective medications, we looked more closely at variations in patient-specific dosages of one expensive and essential agent, insulin, which was taken by 79 continuously enrolled patients who had more than four prescriptions for insulin filled in the year before the cap. These analyses also considered whether precap doses had been excessive, whether observed changes in aggre- gate use were concentrated among a few patients, and the process by which reductions in prescriptions occurred. The average decrease in dose attributable to the cap was 28 percent, or 490 units per patient per month. Only 2 of the 79 patients completely stopped receiving insulin through Medicaid during the cap period, and $l$ of these received insulin again after the cap was lifted. Among those who continued to receive some insulin through Medicaid, nearly half had decreases of more than 25 percent in their average monthly doses and a quarter had decreases of more than 50 percent.

Figure 2 shows the average monthly doses (top half) and prescription sizes (lower half) for two groups of patients: those $(n=36)$ whose doses of insulin were maintained ( $\leqslant 10$ percent drop in average monthly dose), and those $(\mathrm{n}=32)$ with large reductions in dose (>30 percent drop; mean, 68 percent). Both groups had similar precap dosages, suggesting that a reduction in excessive doses was not an underlying explanatory factor. Changes in eligibility also do not explain these effects, since both groups were continuously enrolled in the Medicaid program during the
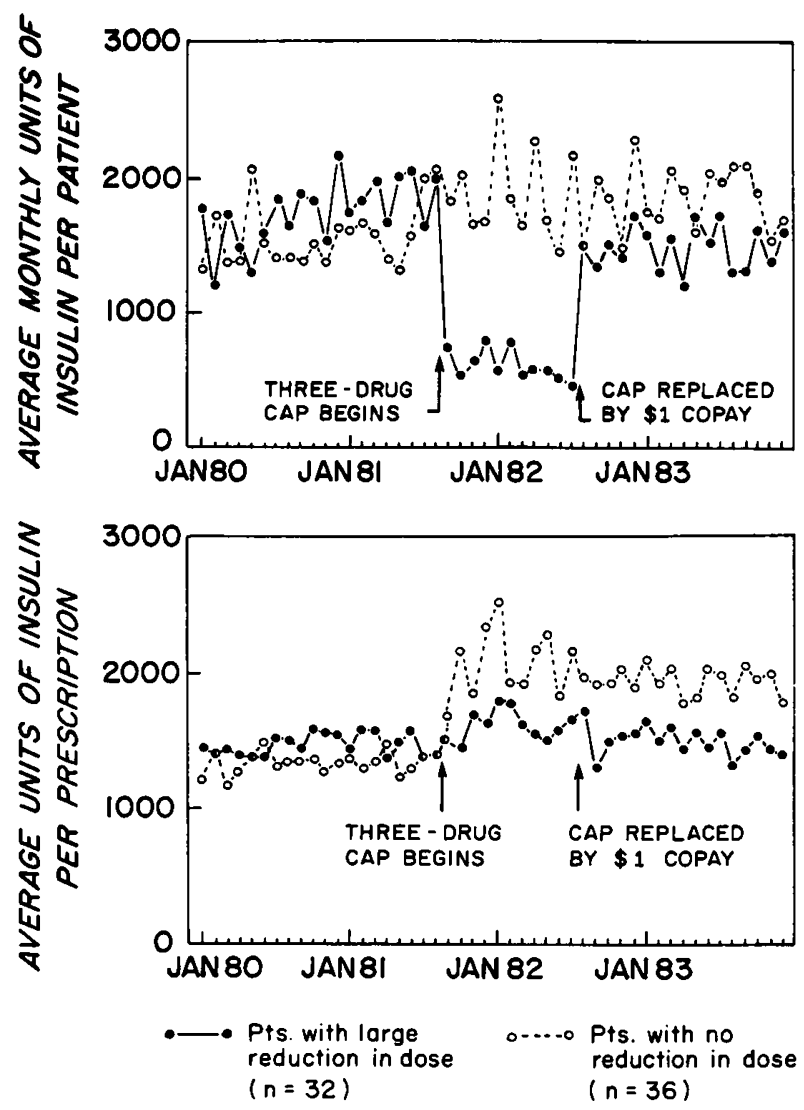

Figure 2. Changes in Average Monthly Insulin Doses (Top) and Prescription Size (Bottom) among Two Groups of Patients with Diabetes Receiving Multiple Drugs.

Patients with large reductions in reimbursed insulin ( $>30$ percent) are indicated by closed circles and patients whose reimbursement for insulin was maintained ( $<10$ percent drop) by open circles. 
study period. However, as Figure 2 indicates, patients with large reductions in dose had only a 9 percent increase in prescription size to compensate for the cap, whereas those whose insulin doses were maintained had 55 percent increases. Thus, sudden declines in insulin use were due to less frequent purchases uncompensated for by large increases in prescription size.

As in the aggregate-drug series, the average insulin doses began to revert to previous levels when the cap was eliminated. This rise in use provides further evidence that the drop in dose coincident with the cap was not due to intentional changes in management strategy by physicians. This conclusion is also supported by analyses of several other essential drugs (e.g., furosemide).

\section{Out-of-Pocket Payments by Medicaid Recipients}

In our review of all out-of-pocket payments at one pharmacy, we identified 10 patients who had more than three prescriptions filled per month before the cap. Including both Medicaid-reimbursed and out-ofpocket prescriptions, this group's use of medications dropped suddenly from 4.9 to 3.1 constant-size prescriptions per patient per month (37 percent). Nine of the 10 patients paid an average of only $\$ 1.36$ per month more themselves to compensate for an average drop in reimbursements of about $\$ 20$ per month, whereas one patient with chronic pulmonary disease increased out-of-pocket purchases by $\$ 70$ per month.

\section{Economic Consequences for Patients and the Medicaid Program}

The economic effects of the policies on the total drug budget of the New Hampshire program, as well as on recipients of multiple drugs, are shown in Figure 3 . Among the patients, the cap caused average reimbursements to drop from $\$ 50$ per month to $\$ 31$ (38 percent), an annual reduction per patient of $\$ 228$. After copayments were instituted, expenditures rose in both level ( $\$ 4$ per month) and slope ( $\$ 0.38$ per month) to a level of $\$ 40$ per month by the end of the 48 months.

From the perspective of the total Medicaid drug budget, the cap achieved an average drop in drug expenditures (after the nursing home exemption) of $\$ 1.87$ per eligible person per month (19 percent) (Fig. 3 ). Since the number of eligible persons during the cap and copayment periods remained approximately constant at an average of 34,922 patients, we estimated that there was a saving in medication reimbursements of about $\$ 780,000$ per year for New Hampshire Medicaid as a result of the cap policy. The independent effects of the copayment on drug expenditures are less clear (Fig. 3). Average prescription rates increased in relation to the cap (Fig. 1) and were approximately as high as precap levels by the end of the copayment period. However, Medicaid paid $\$ 1$ less per prescription received by all patients eligible for Medicaid (except those in nursing homes). Thus, if one assumes conservatively that the copayment did not inhibit the

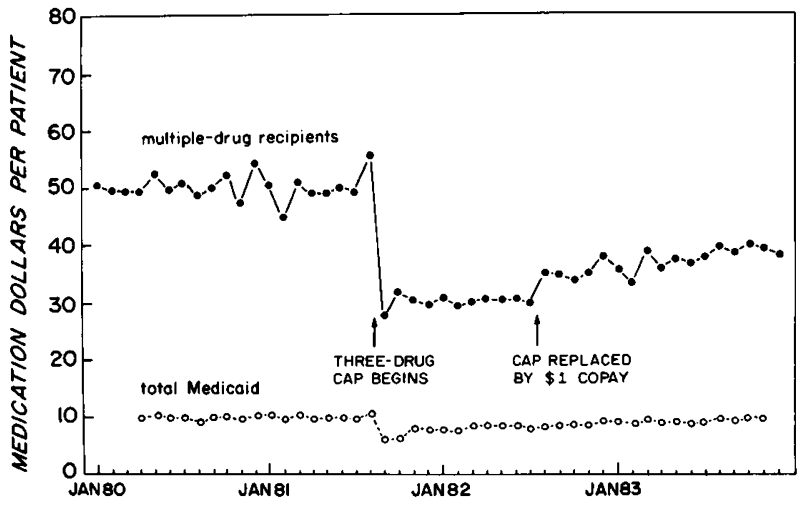

Figure 3. Time Series of Average Medicaid Drug Expenditures per Patient in the Cohort of Multiple-Drug Recipients $(\mathrm{N}=860)$ as Compared with the Total Medicaid Program.

Denominators for the total Medicaid program are the total numbers of persons eligible for Medicaid each month, including those in nursing homes. This total remained stable at about 34,900 during the cap and copayment periods. All medication reimbursements were adjusted to February 1982 dollars on the basis of the consumer price index for prescription drugs. ${ }^{24}$

acquisition of prescriptions as compared with no costcontainment policy, the Medicaid program saved about $\$ 400,000$ per year in total drug expenditures.

The above estimates of dollars saved do not take into consideration either possible increased costs for the patient or possible increases in the use of other health care services necessitated by the withdrawal of essential drugs.

\section{Discussion}

Despite provisions in the prescription-cap regulation that made it possible to circumvent its effect on medication use, both constant-size prescriptions and costs fell substantially among 10,734 continuously eligible outpatients in the New Hampshire Medicaid program. A subgroup consisting of predominantly female elderly or disabled patients taking numerous drugs for long-term conditions was most affected. These findings raise important questions about the potential clinical consequences of such reductions but cannot address them directly. There was some evidence of an attempt to assign priorities for the relinquishment of drugs, since ineffective and less costly drugs were discontinued at a somewhat higher rate than costly or life-sustaining drugs. It is not possible to discern the relative contributions to this process of decisions by physicians, patients, and pharmacists.

Analyses of the numbers of Medicaid prescriptions filled are not a perfect proxy measure of actual medication use; not all medications obtained are consumed, and out-of-pocket purchases are not recorded in Medicaid data bases. However, previous studies have documented reductions in the use of antihypertensive drugs by poor patients after their loss of Medicaid coverage, due to their inability to pay for prescriptions themselves. ${ }^{5,25,26}$ One national survey indicated that among poor patients with fair or poor 
health, uninsured persons received less than half the amount of prescription drugs received by patients with full Medicaid coverage. ${ }^{27}$ The Rand studies also documented the inhibitory effect of cost sharing on the use of medications and other health care. ${ }^{6-9}$ Current federal data indicate that a typical elderly person with a low income has an average of $\$ 36.50$ per month left after paying for necessities such as food, clothing, housing, transportation, and other health care. ${ }^{10,28}$ Thus, in our sample of patients receiving multiple drugs, the average drop of about $\$ 20$ in payments for medications may represent more than half of all the remaining disposable income each month.

Could the drops in prescriptions filled for essential drugs have resulted primarily from decreases in inappropriate use? This would imply reasoned actions in which physicians made decisions to discontinue a specific drug completely or to reduce its dose. Our patient-specific analyses indicated that this was generally not the case. Most patients continued to acquire their medications, but less frequently. Patients (and providers) who were not able to "work the system" had large decreases in prescriptions for essential medications. The rapid increase in prescriptions after elimination of the cap suggests that physicians' reassessments of therapeutic needs were not the main reason for the changes observed.

A particularly troublesome question relates to the minimal compensatory response in prescription size. Several explanations are plausible. First, some officebased physicians may be too busy to keep up to date on the intricacies of Medicaid regulations. In addition, increasing the prescription size requires an alteration in prescribing behavior for some patients but not others. Elderly or poor patients may be reluctant to discuss their level of financial need or embarrassed to ask for special privileges.

The data are quite different with respect to copayment. We cannot estimate the independent effects of this policy in an otherwise "pure" environment, because it replaced the more restrictive cap policy. However, the sudden discontinuities in trend at this time clearly indicate that most drugs were more likely to be reimbursed under the copayment policy than under the cap policy. Copayment still reduced Medicaid drug expenditures, because increases in expenditures for multiple-drug recipients after the lifting of the cap were partly outweighed by the $\$ 1$-per-prescription payments by other Medicaid patients. Thus, a copayment policy appears to discriminate less against the elderly and disabled than a cap policy. Nevertheless, more data on the independent effects of copayments on essential-drug use are needed. ${ }^{29}$ In a group with an average total income of about $\$ 350$ per month for all purposes, ${ }^{10}$ any increased financial demand poses the risk of reduced use of needed therapy.

The effects of such policies on health status and possible substitutions of more intensive medical care remain unknown. Our findings are conservative, in that patients who died or entered nursing homes were not represented in the patient-specific analyses. In addition, these data raise important questions of equity. Quota-type restrictions that ignore health status discriminate against elderly and disabled patients with a high use of health care services.

Primum non nocere (first do no harm) is one of the principal tenets of medical practice. It is not unreasonable to expect health policy makers to assess the potential unintended harm to patients that may result from previously untested innovations. This is often not possible prospectively. One of the few randomized trials conducted, the Rand Health Insurance Experiment, ${ }^{6-8}$ underrepresented the most vulnerable old and poor populations, thus limiting the generalizability of its findings to the groups of greatest concern. The New Hampshire data provide a unique "natural experiment" from which to gain understanding of the effect of benefit reductions in these important populations.

By 1984,14 states had prescription caps in effect an increase of 75 percent since $1981 .{ }^{10}$ New government initiatives to reduce Medicaid costs further may increase the implementation of such policies. Other physician-oriented educational strategies are available to contain costs, and they may be more cost effective in eliminating unnecessary drug use without introducing the potential for adverse clinical consequences. ${ }^{13,15-17}$ More research is needed on the benefits and risks for both patients and the health care system of existing and proposed paymentrestriction policies, to make it possible to reduce unnecessary expenditures while preserving those that are needed, particularly for the nation's most vulnerable patients.

We are indebted to the Medicaid programs of New Hampshire and New Jersey for making the data available for analysis; to Penny Pine of the Health Care Financing Administration for helpful suggestions throughout the project; to Programs and Analysis, Inc., Taeseon Jeon, and Daniel Gilden for programming and data processing; to Sharon Hawley for tabulation of the data; and to Susanne Bellavance for technical assistance.

\section{REFERENCES}

1. Iglehart JK. Medical care of the poor - a growing problem. N Engl J Med 1985; 313:59-63.

2. Lohr KN, Brook RH, Goldberg GA, Chassin MR, Glennan TK. Impact of Medicare prospective payment on the quality of medical care: a research agenda. Santa Monica, Calif.: Rand Corporation, 1985. (Rand publication no. R-3242-HCFA.)

3. Bovbjerg RR, Holahan J. Medicaid in the Reagan era: federal policy and state choices. Washington, D.C.: Urban Institutes Press, 1982:23-62.

4. Temin P. Taking your medicine: drug regulation in the United States. Cambridge, Mass.: Harvard University Press, 1980.

5. Lurie N, Ward NB, Shapiro MF, Brook RH. Termination from Medi-Cal does it affect health? N Engl J Med 1984; 311:480-4.

6. Newhouse JP, Manning WG, Morris CN, et al. Some interim results from a controlled trial of cost sharing in health insurance. N Engl J Med 1981; 305:1501-7.

7. Brook RH, Ware JE Jr, Rogers WH, et al. Does free care improve adults' health? Results from a randomized controlled trial. N Engl J Med 1983; 309:1426-34.

8. Lohr KN, Brook RH, Kamberg CJ, et al. Use of medical care in the Rand Health Insurance Experiment: diagnosis- and service-specific analyses in a randomized controlled trial. Med Care 1986; 24:Suppl:S1-S87.

9. Siu AL, Sonnenberg FA, Manning WG, et al. Inappropriate use of hospitals in a randomized trial of health insurance plans. N Engl J Med 1986; 315:1259-66. 
10. Office of the Actuary, Division of Medicaid Cost Estimates. Analysis of state Medicaid program characteristics, 1984. Baltimore, Md.: Health Care Financing Program Statistics, Health Care Financing Administration, 1985.

11. Drug utilization in office practice by age and sex of the patient: national ambulatory medical care survey, 1980. In: Advance Data from Vital and Health Statistics, no. 81. Hyattsville, Md.: Public Health Service, 1982. (DHHS publication no. (PHS) 82-1250.)

12. Federspiel CF, Ray WA, Schaffner W. Medicaid records as a valid data source: the Tennessee experience. Med Care 1976; 14:166-72.

13. Soumerai SB, Avom J. Efficacy and cost-containment in hospital pharmacotherapy: state of the art and future directions. Milbank Mem Fund Q 1984; 62:447-74.

14. Cook TD, Campbell DT. Quasi-experimentation: design and analysis issues for field settings. Boston: Houghton Mifflin, 1979.

15. Avorn J, Soumerai SB. Improving drug-therapy decisions through educational outreach: a randomized controlled trial of academically-based "detailing." N Engl J Med 1983; 308:1457-63.

16. Schaffner W, Ray WA, Federspiel CF, Miller WO. Improving antibiotic prescribing in office practice: a controlled trial of three educational methods. JAMA 1983; 250:1728-32.

17. Soumerai SB, Avorn J. Economic and policy analysis of university-based drug "detailing." Med Care 1986; 24:313-31.

18. U.S. Department of Commerce, National Technical Information Service. Medicaid data as a source for postmarketing surveillance information. Vol. I: technical report. Prepared by Research Triangle Institute, Research Triangle Park, N.C., for the U.S. Food and Drug Administration. Contract no. 223-82-3021, 1984.
19. Anderson S, Auquier A, Hauck WW, et al. Statistical methods for comparative studies: techniques for bias reduction. New York: John Wiley, 1980

20. American Medical Association Division of Drugs. AMA drug evaluations. 5th ed. Chicago: American Medical Association, 1983.

21. Mulrow CD, Feussner JR, Velez R. Reevaluation of digitalis efficacy: new light on an old leaf. Ann Intern Med 1984; 101:113-7.

22. Gillings D, Makuc D, Siegel E. Analysis of interrupted time series mortality trends: an example to evaluate regionalized perinatal care. Am J Public Health $1981 ; 71: 38-46$.

23. SAS Institute. SAS user's guide: statistics. 1982 edition. Cary, N.C.: SAS Institute, 1982.

24. Bureau of Labor Statistics. Consumer price index, all urban consumers, U.S. city average, prescription drugs. Washington, D.C.: U.S. Department of Labor, 1984.

25. Lurie N, Ward NB, Shapiro MF, Gallego C, Vaghaiwalla R, Brook RH Termination of Medi-Cal benefits: a follow-up study one year later. N Engl J Med 1986; 314:1266-8.

26. Wicher JB, Fihn SD. Withdrawing routine medical outpatient services effects on access and health. Clin Res 1985; 33:269A. abstract.

27. Wilensky GR, Berk ML. Health care, the poor, and the role of Medicaid. Health Aff 1982; 1(4):93-100.

28. U.S. Department of Labor, Bureau of Labor Statistics. Consumer expenditure survey, table 18: selected characteristics and annual expenditures of urban consumer units classified by age of householder and income before taxes, interview survey, 65 and over, 1980-81. Washington, D.C.: Government Printing Office, 1985. (Bulletin no. 2225.)

29. Reeder CE, Nelson AA. The differential impact of copayment on drug use in a Medicaid population. Inquiry $1985 ; 22: 396-403$.

\section{CASE RECORDS}

OF THE

\section{MASSACHUSETTS GENERAL HOSPITAL}

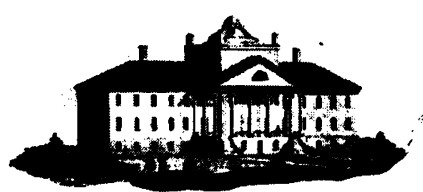

Weekly Clinicopathological Exercises

FOUNDED BY RICHARD C. CABOT

Rober't E. Scully, M.D., Editor

Eugenf. J. Mark, M.D., Associate Editor

William F. McNeely, M.D., Associate Editor

Betty U. McNeely, Assistant Editor

\section{CASE 35-1987}

\section{Presentation of Case}

A 21-year-old woman was admitted to the hospital because of a mass in the right hepatic lobe.

The patient's menarche began at the age of 16 years, with flow that lasted two or three days and was not preceded by molimina. At the age of 18 years her menses ceased at a time that her weight fell from 50 to $42.3 \mathrm{~kg}$ during travel to Europe. Several months later she regained the lost weight, but amenorrhea persisted. During the two years before admission brief courses of various hormonal preparations were administered elsewhere; they included medroxyprogesterone, estrogens, thyroid hormone, and clomiphene, but no menses ensued. Details of her treatment were not available, but she was not on sustained hormonal therapy at any time. Four months before entry a wedge resection of an ovary was performed at another hospital; microscopical examination of the excised tissue revealed multiple superficial follicle cysts. One month before admission the patient began to experience severe pain in the right upper quadrant and right flank that lasted for minutes to hours and was aggravated by deep breathing and activity but was unrelated to ingestion of food.

Three weeks before entry evaluation elsewhere disclosed that the hematocrit was 40 percent; the whitecell count was 11,900 , with 78 percent neutrophils. The prothrombin time was normal. The bilirubin was $0.3 \mathrm{mg}$ per $100 \mathrm{ml}$ ( $5 \mu \mathrm{mol}$ per liter). The serum aspartate aminotransferase (SGOT) was $76 \mathrm{U}$ (normal, less than 30), the serum alanine aminotransferase (SGPT) $97 \mathrm{U}$ (normal, less than 37), and the alkaline phosphatase $198 \mathrm{U}$ per liter (normal, less than 92). Tests for hepatitis B surface antigen and antibody and for hepatitis B e antibody were negative. An ultrasonographic examination of the abdomen showed a mass, $8 \mathrm{~cm}$, in the right hepatic lobe that was believed consistent with an amebic abscess. Needle aspiration of the mass, performed under ultrasonographic guidance, revealed that it was solid and yielded only blood without pus. Fever and chills occurred during the next few days for the first time and then subsided without recurrence. A computed tomographic (CT) scan of the abdomen disclosed a poorly circumscribed, lowattentuation abnormality that occupied much of the right hepatic lobe; the left hepatic lobe extended into the left upper abdominal quadrant and appeared normal; a right pleural effusion was present. Oral treatment for amebiasis was administered for 20 days, 